\title{
Исследование разреза Кольской сверхглубокой скважины СГ-3 радиоактивными методами
}

\section{Яковлев Ю.Н.}

Геологический институт КНЦ РАН

Аннотация. В статье представлены результаты исследования Кольской сверхглубокой скважины СГ-3 радиоактивными методами. Приведена реальная интенсивность радиоактивности и содержания калия, урана и тория в свитах, толщах и более мелких подразделений разреза. Подтверждено, что интенсивность радиоактивности пород меняется в широких пределах: от 200-300 до 2700-2800 импульсов в минуту. Показано, что для подавляющей части пород радиоактивность определяется содержанием в них тория и урана, а заметный вклад калия характерен лишь для некоторых разновидностей пород протерозойского комплекса.

Ключевые слова: Кольская сверхглубокая скважина, радиоактивные методы исследования, калий, уран, торий.

\section{Study of the section of the Kola superdeep well SG-3 by radioactive methods \\ Yakovlev Yu.N. \\ Geological Institute KSC RAS}

Abstract. The article presents results of studying the Kola Superdeep Borehole SD-3 by radioactive methods. Provided below is the real intensity of radioactivity and contents of potassium, uranium and thorium in suits, sequences and minor units of the section. It is confirmed that the radioactivity intensity of rocks varies in a wide range of 200-300 to 2700-2800 impulses per minute. The paper shows that radioactivity in the vast majority of rocks is determined by the content of thorium and uranium in them, while a marked contribution of potassium is typical of only several rock varieties in the Proterozoic complex.

Keywords: Kola Superdeep Borehole, radioactive methods of study, potassium, uranium, thorium.

\section{Предисловие редакции}

Рукопись данной статьи была подготовлена Юрием Николаевичем Яковлевым для публикации в Трудах ФНС. В октябре 2019 г. Ю.Н. Яковлев ушел из жизни. Все последние годы он занимался обработкой материалов, полученных при бурении Кольской сверхглубокой скважины СГ-3. Мы публикуем эту статью с небольшими редакционными изменениями.

\section{Editor's foreword}

The manuscript of this paper was prepared by Yury Nikolaevich Yakovlev to be published in Proceedings of the Fersman Scientific Session. Yu.N. Yakovlev passed away in October, 2019. He dedicated all of his last years to processing materials obtained in drilling of the Kola Superdeep Borehole SD-3. We publish this paper with minor editorial changes.

\section{Введение}

Использование радиоактивных методов проводилось постоянно в процессе проходки скважины СГ-3 и преследовало различные цели:

а) контроль состояния радиоактивных меток в обсадной колонне труб;

б) оценка состава разбуриваемых пород;

в) детальное расчленение разреза - выделение отдельных слоев, пачек и т.п.

В последний раз такие исследования были проведены в 2002 г. по проекту СГК-2002 по стволу № 4 на всю доступную глубину до 7890 м, за исключением интервала 6760-6885 м, включающего нижнюю часть маярвинской свиты, всю телевинскую свиту и небольшой участок первой ар- 
хейской толщи. Исследования проводились полевым отрядом специалистов из пос. Октябрьский (ОАО МПП ВНИИГИС, Башкортостан) под руководством Г.А. Федорова, при участии сотрудников геологической службы СГ-3 Ю.Н. Яковлева и О.Г. Бадалова, осуществлявших детальное расчленение разреза и характеристику минерального состава пород.

В данной статье кратко рассматриваются следующие вопросы:

1) общее распределение радиоактивности в отдельных подразделениях разреза;

2) вариации содержаний калия (\%), урана и тория (в г/т) в свитах и толщах;

3) влияние глубины на радиоактивность.

\section{Результаты исследования}

Общая радиоактивность пород обусловлена наличием в их составе таких минералов как ортит, титанит и циркон (для содержаний урана и тория), а также слюд и полевых шпатов (для калия). Содержание этих минералов определяет естественную радиоактивность конкретных пород разреза. Сведения о ее уровне в подразделениях СГ-3 приведены в таблице 1 и включают как ранее известные данные (Кольская сверхглубокая..., 1998, гл. 4), так и результаты измерений 2002 г. Конкретные сведения для различных пород показаны в таблице 2 (к сожалению, она характеризует не весь разрез).

Анализ этих материалов показывает, что в пределах каждого подразделения разреза радиоактивность изменяется довольно широко, причем нередко вскрывается более сложное строение отдельных интервалов разреза, чем при его литологической документации. Так, в матертской свите среди монотонных диабазов выделяется интервал (770-895 м, табл. 2) тонкого переслаивания туфов и диабазов, который в предыдущих работах не отмечался (Кольская сверхглубокая..., 1984). Аналогичные уточнения обнаруживаются и ниже, что в целом способствует более детальному расчленению разреза.

Породы матертской и заполярнинской свит, по данным А.А. Кременецкого (Кольская сверхглубокая..., 1998, гл. 4), обладают примерно одинаковой средней радиоактивностью (табл. 1, столбцы 3-5), а по данным СГК-2002 (табл. 1, столбцы 7-9) она заметно ниже, причем только в матертской свите содержание урана и тория почти одинаковые, а ниже по разрезу торий всюду преобладает над ураном. Кроме того, по данным СГК-2002, в матертской свите обнаруживается интервал с более высокой радиоактивностью (табл. 2, интервал 770-895 м).

Породы ждановской свиты обладают более высокой радиоактивностью по данным и 1998, и 2002 гг., однако данные 1998 года примерно в 1.5 раза выше данных 2002 г.

Расположенные ниже по разрезу риодациты в самостоятельный горизонт выделены впервые Ф.П. Митрофановым и др. в 2001 г. (Митрофанов и др., 2001), ранее они включались в состав лучломпольской свиты. Риодациты, имеющие интрузивную природу, обладают повышенной радиоактивностью, несопоставимой с предыдущими свитами (табл. 1). Породы лучломпольской свиты по данным А.А. Кременецкого имеют повышенные значения радиоактивности вследствие включения в их состав радацитов, а по данным СГК-2002 - умеренные значения для доломитов и песчаников (табл. 1). Из расположенных ниже свит по данным 1998 г. породы пирттиярвинской и маярвинской свит имеют примерно одинаковые показатели радиоактивности, а породы кувернеринйокской свиты примерно в 1.5 раза превышают их. По данным 2002 г., породы пирттиярвинской и кувернеринйокской свит имеют примерно одинаковые показатели, а породы маярвинской свиты в 1.5-2.0 раза превышают их. При этом наиболее радиоактивными среди последних являются различные сланцы с хлоритом. Для телевинской свиты данных 2002 г. нет, но по данным 1998 г. конгломераты и песчаники этой свиты обладают наиболее высокими показателями радиоактивности, примерно вдвое превосходящими таковые риодацитов.

Таким образом, в разрезе протерозойского комплекса СГ-3 наблюдается два пика пород с наивысшей радиоактивностью: первый фиксирует начало его формирования, а второй примерно середину, причем первый представлен осадочными породами, а второй - интрузивными.

В архейской части разреза СГ-3 можно сравнивать параметры радиоактивности только первых двух толщ. Согласно предыдущим данным первая толща сложена гнейсами с ВГМ (высокогли- 
ноземистыми минералами), а вторая толща - гнейсами с ВКМ (высококальциевыми минералами). По данным А.А. Кременецкого (Кольская сверхглубокая, 1998, гл. 4), обе толщи (особенно первая) отличаются повышенным содержанием тория, урана и калия. А по данным СГК-2002 содержания всех этих элементов примерно в 1.5-2.0 раза ниже, хотя соотношение элементов примерно те же самые. Что же касается дальнейшей глубины, то для нее имеются только предыдущие сведения (Кольская сверхглубокая, 1998, гл. 1,4) согласно которым нечетные толщи, сложенные гнейсами с высокоглиноземистыми минералами (ВГМ), чередуются с четными толщами гнейсов с высококальциевыми минералами (ВКМ). При этом первые из них имеют более высокие показатели радиоактивности (особенно третья), чем четные, причем принадлежность десятой толщи к этой категории весьма дискуссионна.

Таблица 1. Распределение радиоактивных элементов в разрезе СГ-3.

Table 1. Distribution of radioactive elements in the SD-3 section.

\begin{tabular}{|c|c|c|c|c|c|c|c|c|}
\hline \multirow[b]{2}{*}{ Свиты, толщи } & \multirow[b]{2}{*}{ Глубина, м } & \multicolumn{3}{|c|}{ Данные 1998 г. } & \multicolumn{4}{|c|}{ Данные СГК 2002 г. } \\
\hline & & $\begin{array}{c}\mathrm{K}_{\mathrm{cp}}, \\
\%\end{array}$ & $\begin{array}{c}\mathrm{U} \\
\mathrm{ppm}\end{array}$ & $\begin{array}{c}\text { Th } \\
\text { ppm }\end{array}$ & $\begin{array}{c}\text { ГК } \\
\text { имп/мин }\end{array}$ & K, \% & $\mathrm{U}, \mathrm{ppm}$ & Th, ppm \\
\hline 1 & 2 & 3 & 4 & 5 & 6 & 7 & 8 & 9 \\
\hline \multicolumn{9}{|c|}{ Протерозойский комплекс } \\
\hline Матертская & $0-1059$ & 0.37 & 0.29 & 1.24 & $\frac{222-466}{290.40}$ & $\frac{0.14-022}{0.17}$ & $\frac{0.64-1.03}{0.73}$ & $\frac{0.25-0.95}{0.72}$ \\
\hline Ждановская & $1059-2805$ & 1.24 & 0.90 & 2.63 & $\frac{284-1768}{892.6}$ & $\frac{0.17-1.37}{0.51}$ & $\frac{0.80-2.83}{1.44}$ & $\frac{0.58-3.48}{1.68}$ \\
\hline Заполярнинская & $2805-4673$ & 0.19 & 0.16 & 1.22 & $\frac{275-1673}{369.8}$ & $\frac{0.15-0.88}{0.26}$ & $\frac{0.78-3.70}{0.95}$ & $\frac{0.92-2.74}{1.08}$ \\
\hline Риодациты & $4673-4770$ & - & - & - & 2.793 & 1.18 & 4.87 & 6.55 \\
\hline Лучломпольская & $4770-4844$ & 3.64 & 1.35 & 4.87 & 1.712 & 1.61 & 1.53 & 1.70 \\
\hline Пирттиярвинская & $4844-5642$ & 1.12 & 0.39 & 3.10 & $\frac{753-1827}{951.0}$ & $\frac{0.39-1.43}{0.69}$ & $\frac{1.08-1.99}{1.25}$ & $\frac{1.43-3.26}{1.68}$ \\
\hline Кувернерийокская & $5642-5717$ & 1.73 & 0.35 & 4.49 & $\frac{301-2618}{1466.2}$ & $\frac{0.16-2.17}{1.15}$ & $\frac{0.63-2.74}{1.46}$ & $\frac{0.49-2.91}{1.60}$ \\
\hline Маярвинская & $5717-6835$ & 1.18 & 1.26 & 3.69 & $\frac{719-1.634}{1134.5}$ & $\frac{0.25-0.89}{0.57}$ & $\frac{1.03-3.11}{1.79}$ & $\frac{1.31-5.75}{3.18}$ \\
\hline Телевинская & $6835-6842$ & 1.30 & 3.70 & 12.90 & & & & \\
\hline \multicolumn{9}{|c|}{ Архейский комплекс } \\
\hline I & $6842-7622$ & 2.19 & 2.52 & 7.19 & $\frac{584-2794}{1373.8}$ & $\frac{0.37-0.92}{0.64}$ & $\frac{1.20-7.70}{2.20}$ & $\frac{1.73-10.67}{509}$ \\
\hline II & $7622-9456$ & 1.64 & 2.17 & 5.74 & $\frac{631-1162}{965.7}$ & $\frac{0.37-0.59}{0.50}$ & $\frac{1.21-2.06}{1.75}$ & $\frac{2.46-4.07}{3.52}$ \\
\hline III & $9456-9573$ & 2.18 & 5.15 & 10.67 & & & & \\
\hline IV & 9573-10144 & 2.35 & 3.45 & 7.33 & & & & \\
\hline $\mathrm{V}$ & 10144-10601 & 2.11 & 5.26 & 8.66 & & & & \\
\hline VI & $10601-11416$ & 1.79 & 4.09 & 4.70 & & & & \\
\hline VII & 11416-11602 & 1.71 & 4.70 & 6.91 & & & & \\
\hline Гранитогнейс & $12000-20000$ & 1.80 & 2.18 & 5.17 & & & & \\
\hline
\end{tabular}

Примечание.

1. Столбцы 1, 2 для протерозойского комплекса - по (Митрофанов и др., 2001).

2. Столбцы 1, 2 для архейского комплекса, а также столбцы 3-5 - по (Кольская сверхглубокая..., 1998, гл. 4, табл. 4, 5).

3. В столбцах 6-9 над чертой - пределы измерений, под чертой - средние значения.

На рисунке 1 показано распределение общей радиоактивности (ГК ср.) в СГ-3 по данным СГК-2002, а на рисунке 2 - всех ее составляющих (K, U и Th). 
Таблица 2. Распределение радиоактивных элементов в разрезе СГ-3 по данным СГК (2002).

Table 2. Distribution of radioactive elements in the SD-3 section, according to SDK data (2002).

\begin{tabular}{|c|c|c|c|c|c|c|}
\hline Интервал, м & $\begin{array}{c}K_{\mathrm{cp}} . \\
\text { имп/мин }\end{array}$ & $\begin{array}{c}\mathrm{K}_{\mathrm{cp}}, \\
\%\end{array}$ & $\begin{array}{l}\mathrm{U}_{\mathrm{cp}}, \\
\mathrm{ppm}\end{array}$ & $\begin{array}{c}\mathrm{Th}_{\mathrm{cp}}, \\
\mathrm{ppm}\end{array}$ & Породы & $\begin{array}{l}\text { Свиты } \\
\text { Толщи } \\
\end{array}$ \\
\hline 1 & 2 & 3 & 4 & 5 & 6 & 7 \\
\hline $14.5-340$ & 222 & 0.15 & 0.67 & 0.65 & Диабазы, редкие прослои туфов & \multirow{4}{*}{$\mathrm{mt}$} \\
\hline $340-770$ & 315 & 0.18 & 0.72 & 0.76 & Диабазы, прослои порфиритов и туфов & \\
\hline $770-895$ & 466 & 0.22 & 1.03 & 0.95 & Переслаивание туфов и диабазов & \\
\hline $895-1065$ & 230 & 0.14 & 0.64 & 0.55 & Диабазы, редкие прослои туфов & \\
\hline $1065-1160$ & 898 & 0.38 & 1.78 & 1.53 & Туфы пелитовые и алевритовые, филлиты & \multirow{17}{*}{$\mathrm{gd}$} \\
\hline $1160-1185$ & 308 & 0.12 & 0.85 & 1.04 & Порфириты пироксеновые & \\
\hline $1185-1330$ & 1158 & 0.59 & 1.87 & 1.76 & Филлиты, алевролиты углеродистые & \\
\hline $1330-1428$ & 829 & 0.41 & 1.32 & 1.94 & Габбро-диабазы эссекситовые & \\
\hline $1428-1555$ & 1160 & 0.53 & 1.97 & 1.65 & Алевролиты, филлиты & \\
\hline $1555-1685$ & 234 & 0.13 & 0.58 & 0.67 & Гипербазиты серпентинизированные & \\
\hline $1685-1765$ & 960 & 0.49 & 1.46 & 1.65 & Алевролиты углеродистые, песчаники & \\
\hline $1765-1800$ & 400 & 0.16 & 0.97 & 1.13 & Гипербазиты серпентинизированные & \\
\hline $1800-1887$ & 527 & 0.23 & 1.05 & 1.28 & Туфы, алевролиты, диабазы & \\
\hline $1887-2137$ & 400 & 0.24 & 0.78 & 0.80 & До 1985 - туфы, диабазы; ниже-габбро-диабазы & \\
\hline $2137-2267$ & 1768 & 1.00 & 2.21 & 2.88 & Алевролиты, песчаники, филлиты & \\
\hline $2267-2325$ & 206 & 0.15 & 0.50 & 0.48 & Габбро-диабазы & \\
\hline $2325-2490$ & 1618 & 0.98 & 1.99 & 3.16 & Песчаники, алевриты, филлиты & \\
\hline $2490-2560$ & 202 & 0.17 & 0.50 & 0.52 & Габбро-диабазы & \\
\hline $2560-2645$ & 1771 & 1.20 & 2.83 & 3.86 & Песчаники, алевролиты, филлиты & \\
\hline $2645-2757$ & 347 & 0.32 & 0.80 & 0.73 & Габбро-диабазы & \\
\hline $2757-2807$ & 1834 & 1.37 & 3.14 & 3.48 & Песчаники, филлиты & \\
\hline $2808-3595$ & 331 & 0.24 & 0.96 & 0.97 & Диабазы измененные, шаровые лавы & \multirow{8}{*}{ zp } \\
\hline $3595-3650$ & 567 & 0.29 & 1.32 & 2.25 & Диабазы актинолитизированные & \\
\hline $3650-3688$ & 340 & 0.15 & 1.10 & 1.32 & Диабазы порфиробластические & \\
\hline $3688-3713$ & 1108 & 0.78 & 2.19 & 2.74 & Туфы, туффиты & \\
\hline $3713-3756$ & 261 & 0.15 & 0.87 & 0.92 & Диабазы актинолитизированные & \\
\hline $3756-3765$ & 1673 & 0.88 & 3.70 & 3.52 & Туфы, туффиты, диабазы & \\
\hline $3765-4460$ & 275 & 0.22 & 0.78 & 0.80 & До 3790 - диабазы, туфы; ниже - габбро-диабазы, лавы & \\
\hline $4460-4673$ & 651 & 0.38 & 1.09 & 1.75 & Диабазы, туфы.4585-4670-тальк-хлоритовые сланцы & \\
\hline $4673-4770$ & 2793 & 1.18 & 4.87 & 6.55 & Дацитовые порфиры & $\mathrm{rd}$ \\
\hline $4770-4844$ & 1712 & 1.61 & 1.53 & 1.70 & Доломиты, песчаники арказовые, сланцы & lch \\
\hline $4844-5642$ & 825 & 0.51 & 1.25 & 1.88 & Сланцы по диабазам, андезитовые порфириты & prt \\
\hline $5642-5717$ & 549 & 0.40 & 0.84 & 1.18 & Сланцы по диабазам & $\mathrm{kv}$ \\
\hline $5717-5760$ & 1079 & 0.30 & 2.79 & 2.76 & Андезиты (альбитофиры) & \\
\hline $5760-5823$ & 757 & 0.39 & 1.23 & 1.96 & Сланцы по диабазам, туфам; андезиты & \\
\hline $5823-5835$ & 1827 & 1.43 & 1.86 & 3.26 & Метаандезиты & \\
\hline $5835-5840$ & 1351 & 0.90 & 1.99 & 2.88 & Сланцы по ортофирам & \\
\hline $5840-5915$ & 952 & 0.76 & 1.08 & 1.43 & Андезиты и сланцы по ним & \\
\hline $5915-5940$ & 753 & 0.51 & 1.08 & 1.04 & Сланцы по диабазам & \\
\hline $5940-5955$ & 1662 & 0.90 & 2.74 & 2.91 & Сланцы по алевролитам & \\
\hline $5955-5985$ & 301 & 0.16 & 0.63 & 0.49 & Сланцы тремолит-карбонатные & \\
\hline
\end{tabular}




\begin{tabular}{|l|c|l|l|l|l|}
\hline $5985-5917$ & 2618 & 2.17 & 2.13 & 2.51 & Кварцито-песчаники, сланцы по ним \\
\hline $5917-5978$ & 1019 & 0.59 & 1.58 & 1.44 & Амфибол-плагиоклазовые сланцы по вулканитам \\
\hline $5978-5987$ & 1634 & 0.62 & 3.11 & 3.04 & Биотит-плагиоклазовые, сланцы с куммингтонитом \\
\hline $5987-6000$ & 802 & 0.38 & 1.40 & 1.31 & Сланцы с биотитом и хлоритом \\
\hline $6000-6220$ & 1110 & 0.89 & 1.48 & 1.86 & Амфибол-плагиоклазовые сланцы с хлоритом \\
\hline $6220-6263$ & 1033 & 0.48 & 1.21 & 5.02 & Меланократовые сланцы с биотитом \\
\hline $6263-6290$ & 719 & 0.31 & 1.03 & 3.03 & Амфибол-плагиоклазовые сланцы \\
\hline $6290-6410$ & 978 & 0.28 & 1.39 & 5.75 & Амфибол-плагиоклазовые сланцы с биотитом \\
\hline $6410-6465$ & 1114 & 0.25 & 3.20 & 4.55 & Меланократовые сланцы с хлоритом, биотитом \\
\hline $6465-6565$ & 1551 & 0.47 & 2.62 & 4.97 & Амфибол-плагиоклазовые сланцы \\
\hline $6565-6765$ & 1278 & 0.47 & 2.12 & 3.70 & Амфибол-плагиоклазовые сланцы с хлоритом \\
\hline $6765-6766$ & 1417 & 0.58 & 2.18 & 3.92 & Биотит-плагиоклазовые сланцы с хлоритом \\
\hline $6766-6815$ & & & & & Измерения не проводились \\
\hline $6815-7622$ & 2734 & 0.49 & 7.70 & 1.73 & Плагиопегматиты с мусковитом и гранатом \\
\hline $7622-7147$ & 1370 & 0.66 & 2.20 & 4.08 & Гнейсы с ВГМ, плагиопегматиты \\
\hline $7147-7210$ & 2489 & 0.92 & 3.90 & 10.67 & Гнейсо-граниты, гнейсы с ВГМ \\
\hline $7210-7480$ & 1282 & 0.58 & 2.03 & 5.37 & Гнейсы с ВГМ, куммингтонитовые сланцы \\
\hline $7480-7500$ & 584 & 0.37 & 1.20 & 2.28 & Амфиболиты сфенсодержащие \\
\hline $7500-7635$ & 1121 & 0.61 & 1.83 & 4.19 & Гнейсы с ВКМ \\
\hline $7635-7745$ & 631 & 0.37 & 1.21 & 2.46 & Амфиболиты (с куммингтонитом, диопсидом) \\
\hline $7745-7930$ & 1162 & 0.59 & 2.06 & 4.07 & Гнейсы с ВКМ \\
\hline
\end{tabular}

По сути дела рисунок 1 иллюстрирует сказанное выше, а рисунок 2 характеризует роль каждой из составляющих. Отчетливо видно, что изменение общей радиоактивности обусловлено главным образом вариациями содержаний тория, примерно вдвое меньшим - урана и незначительным калия. Но для некоторых интервалов разреза (например лучломпольской и кувернеринйокской свит протерозойского комплекса) содержание калия имеет заметное значение. Также отчетливо видна роль тория в повышении радиоактивности гнейсов первой толщи архейского комплекса.

\section{Заключение}

В итоге хотелось бы перечислить ряд вопросов, оставшихся неразрешенными или освещенными недостаточно.

1. Разрез архейского комплекса по данным Кольской ГРЭ включает 10 толщ, он используется и в более поздней монографии по СГ-3 (Архейский комплекс..., 1991). Автор давно сомневается в правильности расчленения разреза, основываясь на взаимном расположении гнейсов и амфиболитов - главных пород архейского комплекса. Исходя из их взаимного расположения в разрезе, я предложил иное строение комплекса, учитывающее и траекторию стволов скважины, как состоящее из 6 различно ориентированных блоков, в основании которых располагаются амфиболиты, а основная часть сложена гнейсами (с ВГМ и ВКМ). Наличие других пород (пегматитов, гипербазитов и др.) при этом не учитывалось - их очень мало. Строение и состав нижнего, 6-го блока, остались неопределенными из-за «отсутствия» нижней границы.

2. Геохронология архейского комплекса СГ-3 весьма неоднозначна и в большинстве датировок ограничивается наиболее древним возрастом 2.90-2.95 млрд. лет. Но Т.Б. Баяновой получен возраст 3.00-3.15 млрд. лет для ксенолитов амфиболитов в верхней средней части разреза архейского комплекса.

3. До недавнего времени в разрезе СГ-3 было установлено общее количество рудных минералов, сопоставимое с таковым во всем Печенгском рудном поле. Но только в последние годы в Печенгском рудном поле было открыто значительное количество минералов ЭПГ. Таких исследова- 


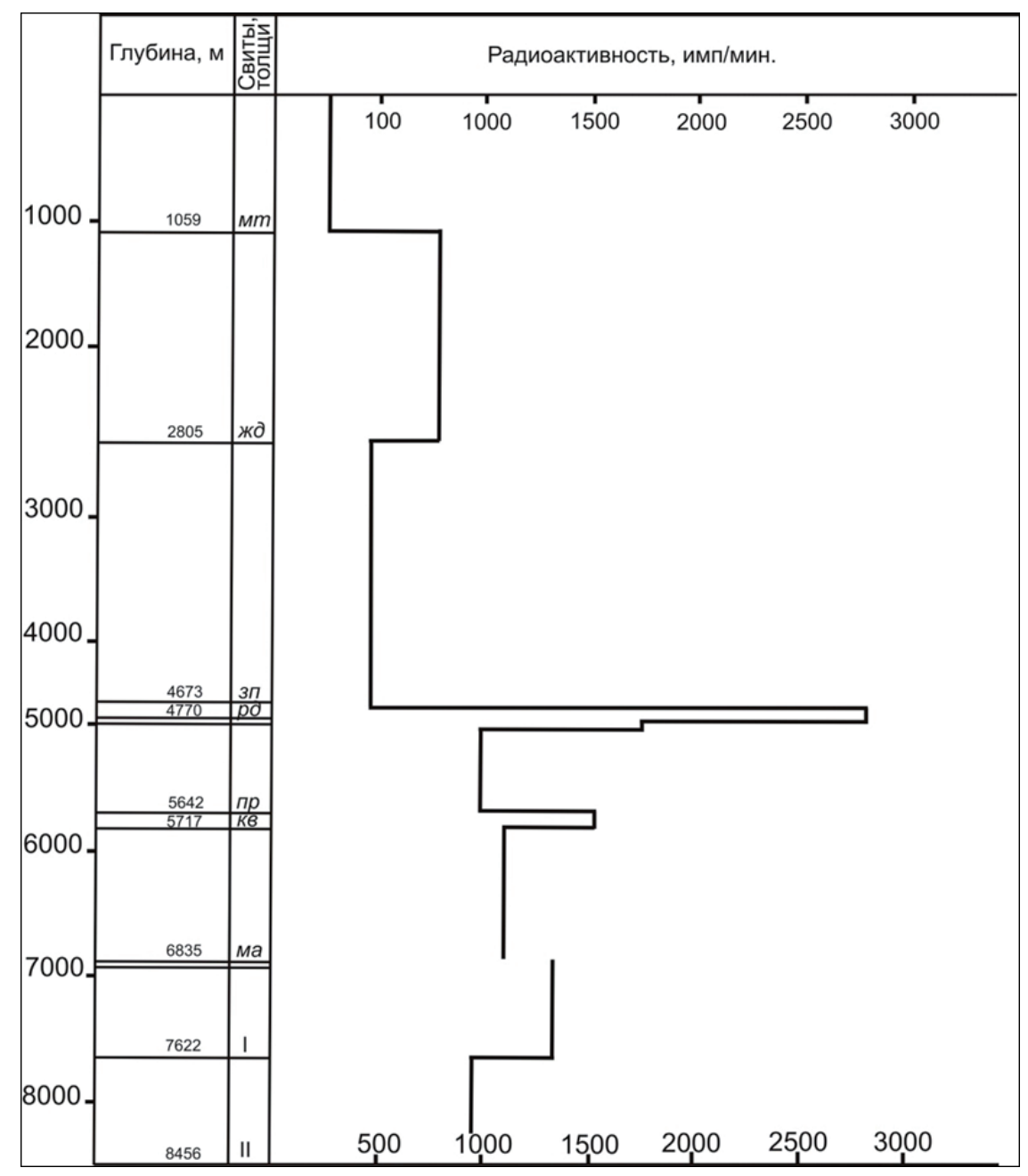

Рис. 1. Средняя естественная радиоактивность свит и толщ разреза СГ-3 (данные СГК, 2002 г.). Свиты протерозойского комплекса: $м m$ - матертская, жд - ждановская, зn - заполярнинская, $p д$ - риодациты, лч - лучломпольская, $n p$ - пирттиярвинская, кв - кувернеринйокская, ма - маярвинская, $m л-$ телевинская, I и II - толщи архейского комплекса.

Fig. 1. Average natural radioactivity in suits and sequences of the SD-3 section (SDK data, 2002). Suites of the Proterozoic complex: $м m$ - Matertskaya, жd - Zhdanovskaya, зn - Zapolyarninskaya, $p \partial$ - rhyodacites, лч - Luchlompolskaya, $n p$ - Pirttiyarvinskaya, $\kappa в$ - Kuverneriyokskaya, $м a$ - Mayarvinskaya, $m л-$ Televinskaya, I and II - sequences of the Archean complex.

ний в керне СГ-3 в последнее время не проводилось, они могли бы в будущем принести интересные результаты.

4. Архейский комплекс в других скважинах России (Туймазинской, Миннибаевской, Ульяновской) так детально как в СГ-3 не исследован, так что сопоставлять данные по СГ-3 с другими подобными объектами пока невозможно.

5. Будущим исследователям архейской части разреза СГ-3 предстоит еще много работы, автор перечислил не всё.

\section{Въводы}

1. Доказана возможность проведения радиоактивных исследований в стволе СГ-3, обсаженном колонной стальных труб диаметром 245 мм. Полученные диаграммы обладают высокой контрастностью и хорошей разрешающей способностью, что позволяет выделять интервалы пород мощностью 2-3 м. Не обнаружено влияния каверн в обсадных трубах на четкость записи каротажа.

2. Рассчитаны реальная радиоактивность и содержания калия, урана и тория в свитах, толщах и 


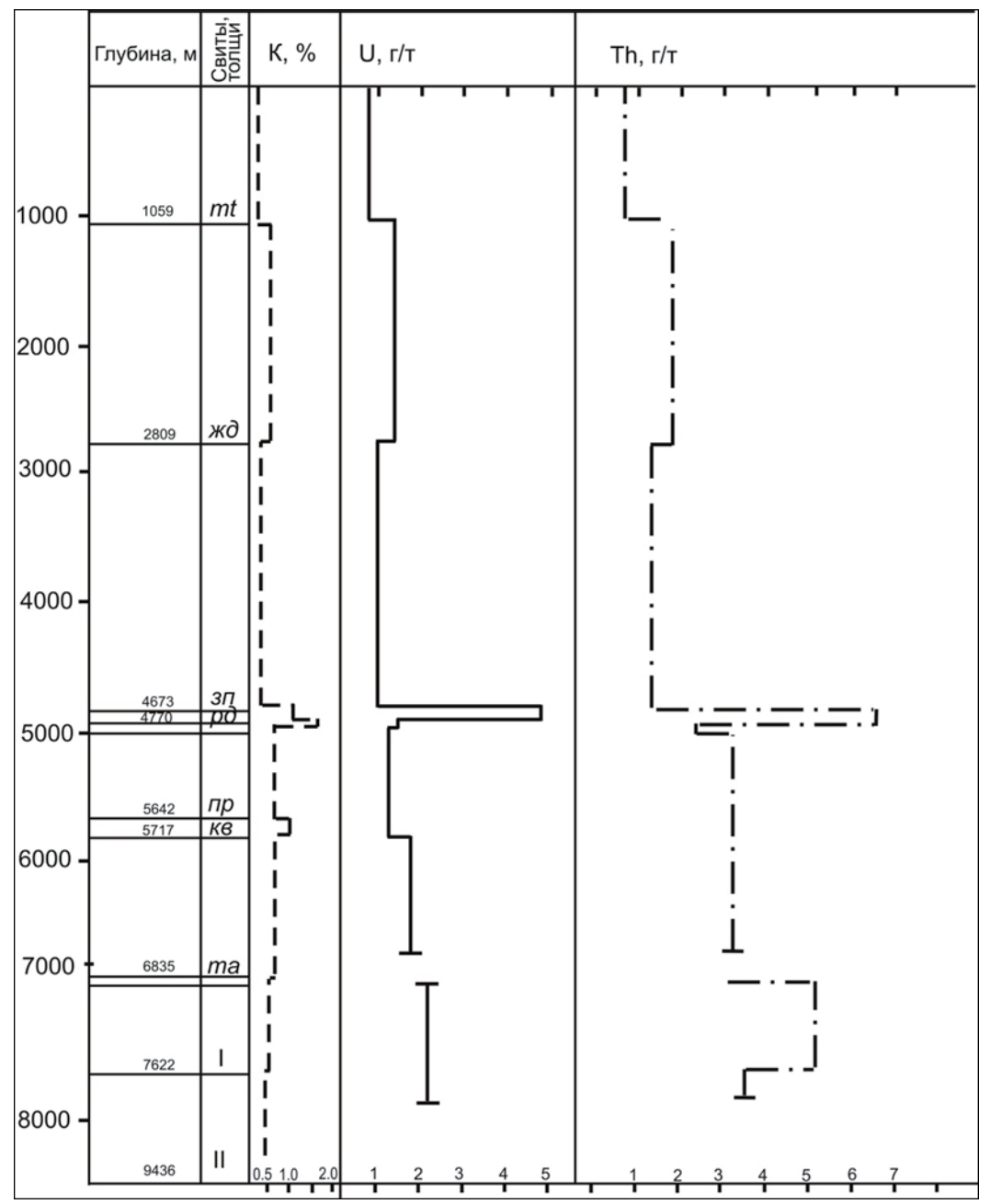

Рис. 2. Распределение К, U и Тh по свитам разреза СГ-3 (данные СГК-2002 г.).

Fig. 2. Distribution of K, U and Th in suites of the SD-3 section (SDK-2002 data).

более мелких подразделений разреза. Подтверждено, что интенсивность радиоактивности пород меняется в широких пределах: от 200-300 до 2700-2800 импульсов в минуту.

3. Показано, что для подавляющей части пород радиоактивность определяется содержанием в них тория и урана, а заметный вклад калия характерен лишь для некоторых разновидностей пород протерозойского комплекса.

4. Примечательно, что согласно предыдущим данным наименее мощные толщи архейского комплекса (III, V и VII), отличаются повышенными содержаниями тория и урана, а также некоторых других элементов (золота, платиноидов и др.).

\section{Литература}

1. Архейский комплекс в разрезе СГ-3 (ред. Ф.П. Митрофанов). Апатиты. Изд-во: КНЦ АН СССР. 1991. 186 с.

2. Кольская сверхглубокая. Исследование глубинного строения континентальной коры с помощью бурения Кольской сверхглубокой скважины (ред. Е.А. Козловский). М. Изд-во: Недра. 1984. 490 с.

3. Кольская сверхглубокая. Научные результаты и опыт исследований (под ред. Н.П. Лаверова, В.П. Орлова). М. Изд-во: МФ ТЕХНОНЕФТЕГАЗ. 1998. 260 с.

4. Митрофанов Ф.П., Скуфьин П.К., Баянова Т.Б. и др. Интрузивное тело риодацитовых порфиров в разрезе пород раннепротерозойского Печенгского комплекса Кольской сверхглубокой скважины // Докл. РАН. 2001. Т. 380. № 4. С. 540-544. 